\title{
Editorial
}

\section{Promoting global health innovation: On the need for global health care solutions in the spirit of the International Conference on Applied Science and Health (ICASH)}

\author{
Andrew J Macnab \\ Editor in Chief, Global Health Management Journal \\ *Corresponding author. Email: ajmacnab@gmail.com \\ Accepted 26 May 2017 \\ (C) 2017 Publications of Yayasan Aliansi Cendekiawan Indonesia Thailand \\ This is an open access following Creative Commons License Deed - Attribution-NonCommercial-ShareAlike 4.0 International (CC BY-NC-SA 4.0)
}

Health and well-being are the fundamental right of every human. While governments of every nation are responsible for the policies and infrastructure that enable people to access health care services, it is now recognized that the innovation necessary to improve health and well-being is something to be conscientiously fostered and directed towards the achievement of particular objectives, [1] and that there is a growing need for bold ideas able to save and improve lives that integrate innovation in science, technology, education and social change.

Where do such ideas come from and who has the responsibility to generate them?

At a global level, agencies such as the United Nations (UN) and World Health Organization (WHO) formulate global polices; the UN Sustainable Goals (SDGs) announced in the document "Transforming our world: the 2030 Agenda for Sustainable Development" is an example of a clear call to action. The SDGs, which supersede the Millennium development goals, incorporate 17 overarching global goals and 169 targets and set a comprehensive agenda, principally to address directly or indirectly needed improvements in human growth, survival and thriving. [2,3]

There is also accumulating evidence from worldwide academic research of the growing need for new ideas, novel programs and more effective interventions. For example, studies on the Developmental Origins of Health and Disease (DOHaD) now convincingly show how early life exposures related to conception, pregnancy, infancy and childhood can have a significant impact on health and disease risk in later life; examples include trends in obesity, type 2 diabetes, heart disease, some cancers and mental illness. [4,5] This new knowledge requires a paradigm shift in how we work to address non-communicable chronic diseases.

At a national level there is a need for political vision, commitment and leadership at the highest level. It is important for experts, practitioners, professionals and academics at universities to provide government and policy makers with clear priorities. For example, millions of deaths would be averted and the economic cost of healthcare reduced if the focus on prevention was greater. [6] It is often economic incentives that prove to be the strongest argument for change. However, in this context there is now robust evidence that investing in health is beneficial to socio-economic development, [2] and that in turn socio-economic development results in better health and human capital.

At all levels, the generation and testing of novel ideas by young investigators is an important 
mechanism for driving scientific and social innovation. Especially where these ideas are bold and involve new approaches or forms of cooperation that can contribute to sustainable health improvements for society.

The sharing of such ideas and exchange of knowledge and experience by young investigators was the aim of the first International Conference on Applied Science and Health (ICASH) held in Bangkok in February 2017. ICASH was a joint initiative designed by the Institute of Population and Social Research at Mahidol University, Thailand, the Doctoral Program in Public Health Science at Diponegoro University, Indonesia, and Universitas 'Aisyiyah Yogyakarta, Indonesia. ICASH brought together experts, practitioners, professionals and students from applied science and health related fields, and what they shared is available in the published conference proceedings registered at National Library of Indonesia and available $<$ http://publications.inschool.id/index.php/icash/in $\underline{\operatorname{dex}}>$

The Global Health and Development Journal was established by the founders of ICASH to be a platform for presenting the outcome of projects intended to define where scientific, educational, technological and social innovation can be applied to improve health. This first edition highlights five of the presentations made at ICASH 2017.

Antarini et al identify unmet need family planning due to birth spacing and limiting situation among reproductive age women in Indonesia. Birth spacing tended to be favored by young mothers, early marriage, had low parity and low education attainment, whilst limiting childbirth tended to be preferred by older mothers with longer marriage experience, high parity, and secondary education attainment.

Suryadinata conducted a systematic review to evaluate the benefits of automated dispensing machine (ADM) use as a potential solution for hospital pharmacy dispensing errors in Indonesia. The 13 studies reviewed describe benefits that included significant reduction in dispensing errors, and also additional benefits of time saving in peak hours and cost savings; all relevant to consideration of installation of ADM in Indonesia.
Diartama et al describe the design of a radiology viewing box using a potentiometer system intended to improve radiograph viewing. The mean viewing box illumination achieved reached 220 lux and enabled optimal radiograph viewing by the radiologists and radiographers evaluating it.

In addition, there is a photo essay on how the World Health Organization 'Health Promoting School' (HPS) model can be used to address the challenges involved in seeking to achieve the UN sustainable development goals (SDGs). Health promotion uses a range of complimentary approaches to provide individuals and communities with the knowledge and skills that will enable them to improve their own health and wellbeing. Encouraging children to adopt healthy lifestyle habits is a central objective, and health promotion at a community level, particularly through use of the WHO 'HPS' model health promoting schools, is a strategy many of us can consider as a means of effectively generating new health knowledge and promoting healthy behaviors. Health promotion and health care initiatives delivered through schools are well within the capacity of low and middle income countries, as they require a change in mindset and refinement of educational objectives rather than provision of major new resources, engagement of nongovernmental resources or obtaining international funding. There is consensus on the validity of the HPS model [7] and a growing literature on the evidence of efficacy and cost savings related to school-based health initiatives.

The Global Health and Development Journal also has another potential role of importance. Currently, there is a gap between our level of knowledge of effective treatments and the healthcare interventions and services being received by people of all ages in many countries. While much is known from research about interventions that are effective, all too often this knowledge does not get translated into policies and practices that improve health outcomes for our children, families and adults in ways that they need and deserve. [8] A process of inquiry is required in parallel with conventional research to improve our understanding of how to implement interventions effectively and enhance service delivery processes at local, state, and national levels. To gain this understanding, evidence-based data of "what works and why" are 
needed. This means that we must develop locally relevant and applicable ways to evaluate how we introduce, deliver and sustain the innovative programs we develop, and have an avenue to report them. The journal will be valuable in this regard, as it will provide a forum for young investigators to describe bold scientific ideas and social innovations able to save and improve lives alongside reports of new forms of cooperation and effective health services delivery. This combination of innovations that integrate science and technology with education and social change together will meet the recognized need for greater understanding of "what works and why" and in turn contribute to more sustainable health improvements for society as a whole.

\section{References}

1. Brook D, MacMaster C, Singer PA. Innovation for development. 2013. https://idl-bncidrc.dspacedirect.org/handle/10625/51577

(Accessed May 22, 2017).

2. United Nations. Transforming our world: the 2020 Agenda for Sustainable Development. United Nations, New $\quad$ York; 2015. https://sustainabledevelopment.un.org/content/do cuments/212520302 Agenda for Sustainable Development web.pdf (Accessed May 11 2017).

3. Sachs JD. From millennium development goals to sustainable development goals. The Lancet. 2012; 379, 9832: 2206-11.

4. Gluckman PD, Hanson MA. The developmental origins of health and disease: an overview. In Developmental Origins of Health and Disease (eds. Gluckman P, Hanson M), 2006; pp. 1-5. Cambridge University Press, Cambridge.

5. International Society for Developmental Origins of Health and Disease. The Cape Town Manifesto - November 2015. International Society for Developmental Origins of Health and Disease, Cape Town; 2015. https://dohadsoc.org/wpcontent/uploads/2015/11/ DOHaD-Society-Manifesto-Nov-17-2015.pdf (Accessed May 15 2017).

6. Bloom DE, Cafiero ET, Jané-Llopis E, AbrahamsGessel S, Bloom LR, Fathima $S$ et al. The Global Economic Burden of Non-communicable Diseases. Geneva: World Economic Forum. 2011

7. Macnab AJ. The Stellenbosch consensus statement on Health Promoting Schools. Global Health Promotion. 2013; 20(1):78-81.
8. Morel CM, Acharya T, Broun D, Dangi A, Elias C, Ganguly NK, et al. Health innovation networks to help developing countries address neglected diseases. Science. 2005; 309(5733):401-4. 